\title{
Исследование сорбционных свойств материалов с помощью физико-химического метода распределения центров адсорбции
}

\author{
® 2019 Байдарашвили M.M., Сахарова А.С. \\ Петербургский государственный университет путей сообщения Императора Александра I, \\ Санкт-Петербург
}

Поступила в редакцию 26.07.2019 г.

DOI: $10.17308 /$ sorpchrom.2020.20/2383

Адсорбция широкого набора индикаторов позволяет получить наглядную картину распределения на поверхности твердого вещества активных центров по их кислотно-основным (донорноакцепторным) свойствам. Метод распределения центров адсорбции (метод РЦА) представляется информативным для прогнозирования селективной адсорбции веществ различной природы на определенных активных центрах. Цель работы заключалась в определении сорбционных свойств некоторых твердых материалов по отношению к катионам тяжелых металлов (КТМ), используя классификационные признаки поверхности в системе метода РЦА и природе загрязняющих веществ.

С помощью метода РЦА были исследованы такие твердые материалы, как пенобетон различной исходной плотности, а также доменный гранулированный шлак. Анализ характера распределения центров адсорбции на поверхности образцов проводился до и после насыщения измельченных образцов растворами, содержащими такие КТМ как $\mathrm{Fe}(\mathrm{III})$ и $\mathrm{Mn}(\mathrm{II})$.

Результаты анализа показали, что на поверхности исходного образца пенобетона плотностью 300 кг/м ${ }^{3}$ наблюдаются два типа адсорбционных центров, соответствующих бренстедовским основаниям $\left(\mathrm{pK} \mathrm{a}_{\mathrm{a}}=6-10.5\right)$ согласно предлагаемой классификации. Поглощение происходило именно в этой области, что экспериментально подтверждается резким понижением содержания указанных типов центров после взаимодействия образца с раствором, содержащим КТМ. На поверхности исходного образца пенобетона плотностью 500 кг/м ${ }^{3}$ можно отметить высокое содержание бренстедовских кислотных и основных центров адсорбции. После пропускания раствора с ионами железа концентрация активных центров в области бренстедовских оснований понизилась, то есть произошла адсорбция ионов железа. При этом содержание бренстедовских кислот осталось практически неизменным, что говорит об избирательности адсорбции. Исследования по определению характера РЦА на поверхности доменного гранулированного шлака (исходного и отработанного) показали, что интенсивность полос адсорбции в области $\mathrm{pK}_{\mathrm{a}}=7.3$ у исходного образца шлака резко снижается после пропускания имитата раствора, что подтверждает поглощение КТМ на бренстедовских основных центрах. Высокое количественное содержание активных центров на поверхности этого материала определяется высокой дисперсностью (фракция <0.08 мм).

Таким образом, результаты интерпретации картин распределения на поверхности исследуемых образцов активных центров по их кислотно-основным свойствам показали, что метод РЦА как физико-химический метод исследования поверхности твердого тела позволяет прогнозировать сорбционные свойства материалов и расширять область их применения.

Ключевые слова: распределение центров адсорбции, бренстедовские и льюисовские центры, кислотно-основной тип, ионы тяжелых металлов, экозащитные свойства, пенобетон, шлак.

\section{Введение}

Сегодня основная задача всей физики поверхности - это количественное исследование микроскопических поверхностных характеристик. Надежное экспери- 
ментальное изучение поверхностных электронных состояний и атомной структуры требует больших усилий и стало возможным лишь в 70-е годы. Все подобные эксперименты основаны на зондировании поверхности каким-либо воздействующим на нее агентом. Как правило, это потоки частиц или электромагнитного излучения, которые называют первичными и которые после взаимодействия с поверхностью несут информацию о ее состоянии. Используют также электрическое и магнитное поля, тепловую энергию тела - колебания атомов решетки - и некоторые химические методы. Наиболее популярные экспериментальные методики - это электронная ожеспектроскопия и дифракция медленных электронов [1-4]. Но большинство химических и физико-химических процессов, протекающих с участием поверхности твердых веществ, носят локальный характер и во многом определяются энергетическими параметрами конкретных активных центров. В связи с этим особую важность приобретает исследование спектра распределения центров адсорбции (РЦА) по кислотноосновному типу и характера его изменения в зависимости от тех или иных условий.

Согласно современным воззрениям, поверхность твердого вещества бифункциональна, так как представляет собой совокупность центров Льюиса и Бренстеда как кислотного, так и основного типов.

Индикаторный метод распределения центров адсорбции (метод РЦА) - это метод изучения поверхности твердого тела, направленный на количественное определение способности твердого вещества адсорбировать соединение определенной кислотно-основной природы из растворов. Впервые метод предложен Нечипоренко А.П. в Петербургском Технологическом университете в 1995 году [5].

Изучая адсорбцию широкого набора индикаторов, можно получить наглядную картину распределения на поверхности твердого вещества активных центров по их кислотно-основным (донорно-акцепторным) свойствам, характеризуемым величиной $\mathrm{pK}_{\mathrm{a}}$. При этом $\mathrm{qpK}_{\mathrm{a}}=\mathrm{f}\left(\mathrm{pK}_{\mathrm{a}}\right)$ - ордината, которая дает представление о количе-

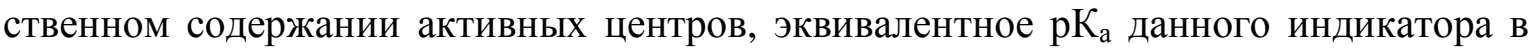
стандартных условиях. $\mathrm{pK}_{\mathrm{a}}$ различных индикаторов может лежать в интервале от -4.4 до +14.2 .

Начальные исследования, проводимые с использованием метода РЦА, были направлены на изучение поверхности оксидных, халькогенидных и металлических систем и ее возможных реакциях [6-8].

Впервые индикаторный метод РЦА выбран в качестве контрольного в области защиты окружающей среды на кафедре «Инженерная химия и естествознание» под руководством Сватовской Л.Б. [9] Петербургского государственного университета путей сообщения Императора Александра I (ПГУПС).

Метод РЦА представляется информативным для прогнозирования селективной адсорбции веществ различной природы на определенных активных центрах, что дает сведения о потенциальных сорбционных свойствах материалов.

Опираясь на знание о механизме образования бренстедовских и льюисовских центров кислотного и основного типов, авторами предложены классификационные признаки поверхности в системе метода РЦА и природе загрязняющих веществ (табл. 1) [10, 11].

Метод РЦА как физико-химический метод исследования поверхности твердых тел может позволить оценить и, следовательно, спрогнозировать их сорбционные свойства к различным видам загрязняющих веществ (табл. 1).

Задачей данной статьи является исследование и выявление сорбционных свойств некоторых материалов, используя физико-химический метод распределения центров адсорбции (метод РЦА). 
Таблица 1. Прогнозирование сорбционных свойств твердых тел по наличию центров адсорбции на поверхности [10].

\begin{tabular}{|c|c|}
\hline Область $\mathrm{pK}_{\mathrm{a}}$ & Тип загрязнения \\
\hline $\begin{array}{l}\text { Льюисовские основные центры } \\
\qquad \kappa_{\mathrm{a}} \leq 0\end{array}$ & $\begin{array}{c}\text { Электроноакцепторные соединения, } \\
\text { образующие донорно-акцепторную связь } \\
\text { (амины, органические катионы и др.) }\end{array}$ \\
\hline $\begin{array}{c}\text { Бренстедовские кислотные центры } \\
0 \div 7\end{array}$ & $\begin{array}{c}\text { Соединения основного характера, } \\
\text { (органические вещества, примеси, связанные } \\
\text { в гидроксокомплексы) }\end{array}$ \\
\hline $\begin{array}{l}\text { Бренстедовские основные центры } \\
7 \div 12\end{array}$ & $\begin{array}{c}\text { Ионы тяжелых металлов } \mathrm{Cr}^{3+}, \mathrm{Mn}^{2+}, \mathrm{Fe}^{3+}, \mathrm{Co}^{2+} \\
\text { и т.д., образующие гидроксиды }\end{array}$ \\
\hline $\begin{array}{l}\text { Льюисовские кислотные центры } \\
\qquad 12 \div 17\end{array}$ & $\begin{array}{c}\text { Электронодонорные соединения, соединения осн } \\
\text { го характера (различные анионы) }\end{array}$ \\
\hline
\end{tabular}

\section{Эксперимент}

В качестве объекта исследования выбран современный строительный материал - пенобетон различной исходной плотности. Компонентный и количественный состав материала представлен в таблице 2.

Таблица 2. Компонентный состав пенобетона [10].

\begin{tabular}{|c|c|c|c|c|}
\hline \multirow{2}{*}{$\begin{array}{c}\text { Плотность } \\
\text { пенобетона, кг/м }\end{array}$} & \multicolumn{4}{|c|}{ Компонентныи состав, \% } \\
\cline { 2 - 5 } & цемент & песок & вода & пена \\
\hline 300 & 17.07 & 2.40 & 8.90 & 71.50 \\
\hline 500 & 31.0 & 3.97 & 11.9 & 53.0 \\
\hline 700 & 33.50 & 10.45 & 15.68 & 40.4 \\
\hline 800 & 34.6 & 13.6 & 11.86 & 40.0 \\
\hline 1000 & 25.3 & 37.5 & 9.6 & 27.5 \\
\hline 1200 & 25.0 & 44.5 & 9.4 & 20.9 \\
\hline
\end{tabular}

Метод РЦА основан на том, что, адсорбируясь, индикатор может менять окраску, которая является мерой кислотности (основности) его поверхности. Полное описание кислотно-основных свойств поверхности твердого вещества подразумевает определение концентрации и силы активных центров, т.е. получение их распределения с дифференциацией на кислоты и основания, а также установление величины ее функции кислотности $[12,13]$.

Концентрацию активных центров (qрК $\left.{ }_{a}\right)$, эквивалентную количеству адсорбированного индикатора кислотной силы $\left(\mathrm{pK}_{\mathrm{a}}\right)$ определяли по формуле (1):

$$
q_{p K_{a}}^{x}=\frac{C_{\text {ind }} \cdot V_{\text {ind }}}{D_{0}}\left(\frac{\left|D_{0}-D_{1}\right|}{a_{2}} \pm \frac{\left|D_{0}-D_{2}\right|}{a_{2}}\right)
$$

где $\mathrm{C}_{\text {ind }}$ - концентрация раствора индикатора, мг/моль-см ${ }^{3} ; \mathrm{V}_{\text {ind }}$ - объем раствора индикатора, взятого для анализа, $\mathrm{cm}^{3} ; \mathrm{D}_{1}$ - оптическая плотность раствора индикатора до сорбции; $\mathrm{D}_{2}$ - оптическая плотность раствора индикатора после сорбции; $\mathrm{D}_{0}-$ оптическая плотность «холостого» раствора; $a_{2}$ - активность акцептора электронной пары.

Характер распределения центров адсорбции на поверхности образцов пенобетона различной исходной плотности представлен на рисунке 1. Наибольшая концентрация активных центров на поверхности пенобетона разной плотности наблюдается в области бренстедовских и льюисовских основных центров. Данный характер РЦА определяется разным количественным составом (табл. 2). 


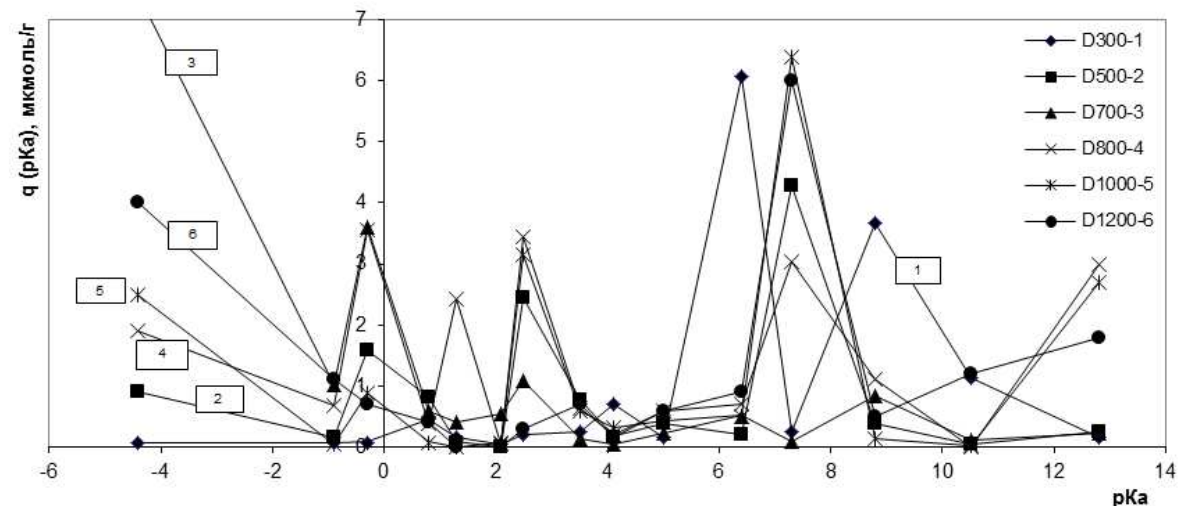

Рис. 1. Распределение центров адсорбции на поверхности измельченного пенобетона разной исходной плотности

Далее проведено насыщение измельченных образцов пенобетонов (фракцией 1.0-0.63 мм) плотностью 300, 500, 700 кг/м ${ }^{3}$ растворами, содержащими катионы $\mathrm{Fe}(\mathrm{III})$ и $\mathrm{Mn}(\mathrm{II})$, и повторном исследовании картины РЦА. Выбор катионов $\mathrm{Fe}(\mathrm{III})$, $\mathrm{Mn}(\mathrm{II})$ в качестве объектов исследования обусловлен распространенностью их в окружающей среде и высокой токсичностью. Определение катионов $\mathrm{Fe}(\mathrm{III}), \mathrm{Mn}(\mathrm{II})$ в растворах проводилось в соответствии с методикой [13].

Количественная характеристика удельной сорбционной емкости равна отношению массы поглощенных ионов к единице массы пенобетона, мг/г, и рассчитывается по формуле Гиббса (2) для емкости [14]:

$$
a=\frac{\left(C_{\text {нач }}-C_{\text {кон }}\right) \cdot V}{m}
$$

где $a$ - сорбционная емкость, мг/г; $\mathrm{C}_{\text {нач }}-$ начальная концентрация модельного раствора, мг/дм ${ }^{3} ; \mathrm{C}_{\text {кон }}-$ конечная концентрация модельного раствора, мг/дм ${ }^{3} ; V-$ объем раствора, взаимодействующий с пенобетоном, дм ${ }^{3} ; m$ - масса измельченного пенобетона, г.

Полученные величины емкостей пенобетона различной плотности представлены в таблице 3, а распределение центров адсорбции на примере пенобетонов плотностью 300 и 500 кг/м³ приведены на рисунках 2, 3.

Таблица 3. Сорбционная емкость пенобетона разной плотности

\begin{tabular}{|c|c|c|c|}
\hline 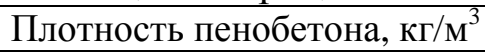 & 300 & 500 & 700 \\
\hline Емкость по Fe (III), мг/Г & 0.70 & 0.55 & 0.22 \\
\hline Емкость по Mn (II), мг/Г & 2.70 & 2.40 & 1.50 \\
\hline
\end{tabular}

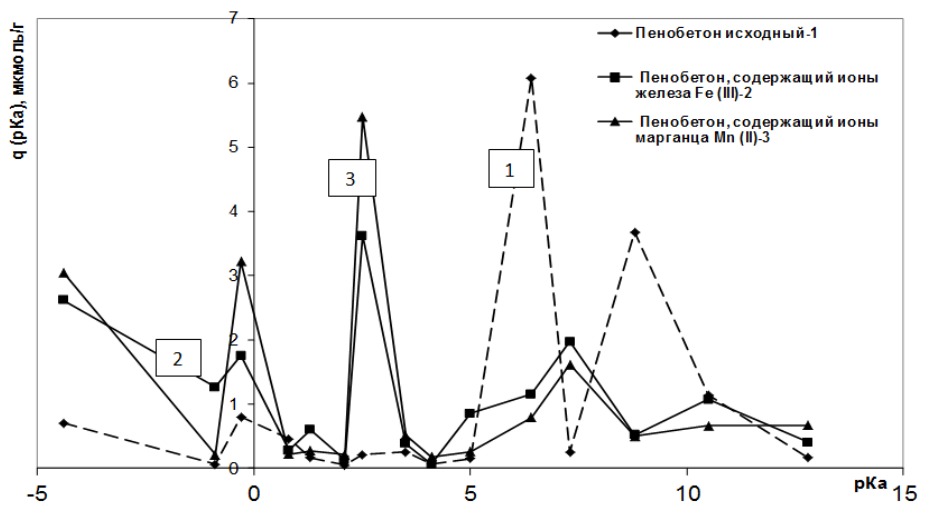

Рис. 2. Картина РЦА на поверхности пенобетона D300 исходного и содержащего ионы тяжелых металлов 


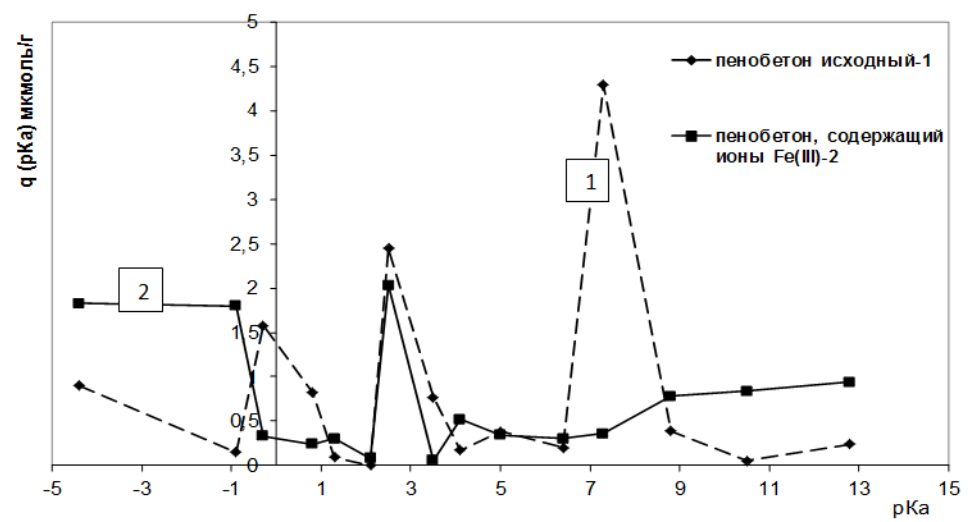

Рис. 3. Распределение центров адсорбции на поверхности пенобетона D500 исходного и содержащего ионы Fe(III)

\section{Обсуждение результатов}

Как видно из рисунка 2, на поверхности исходного образца пенобетона плот-

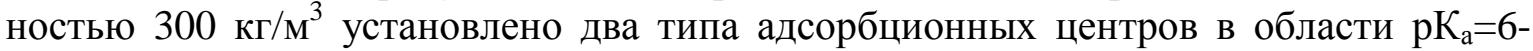
10.5 , соответствующих бренстедовским основаниям, с концентрацией q $\left(\mathrm{pK}_{\mathrm{a}}\right)$ равной 6.1 и 3.7 мкмоль/г. Согласно предлагаемой классификации поглощение катионов $\mathrm{Fe}(\mathrm{III})$ и $\mathrm{Mn}(\mathrm{II})$ должно происходить именно в этой области, что экспериментально подтверждается резким понижением содержания указанных выше типов центров соответственно до 0.8 и 0.5 (по $\mathrm{Mn}^{2+}$ ) и до 1.15 и 0.5 (по $\mathrm{Fe}^{3+}$ ).

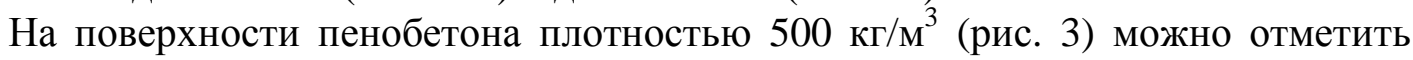
высокое содержание бренстедовских кислотных и основных центров адсорбции $\left(\mathrm{q}\left(\mathrm{pK}_{\mathrm{a}}\right)=2.48\right.$ и 4.32 мкмоль/г). После пропускания раствора с ионами железа концентрация активных центров в области бренстедовских оснований понизилась до q $\left(\mathrm{pK}_{\mathrm{a}}\right)=0.7$ мкмоль/г, что связано с поглощением катионов Fe(III). При этом содержание бренстедовских кислот (рис. 3) осталось практически неизменным, что является результатом избирательности адсорбции.

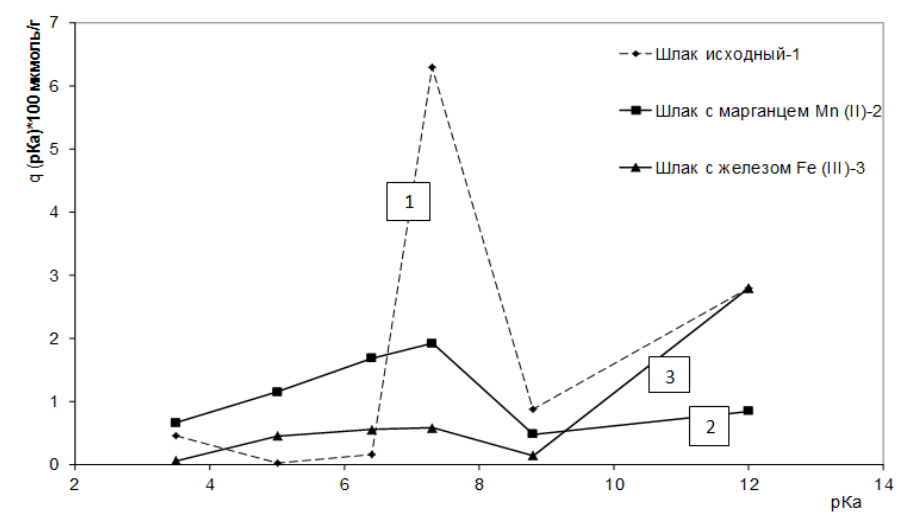

Рис. 4. РЦА на поверхности шлака контрольного и содержащего ионы тяжелых металлов

Исследования по определению характера РЦА на поверхности доменного гранулированного шлака (исходного и отработанного) (рис.4) показали, что интенсивность полос адсорбции в области $\mathrm{pK}_{\mathrm{a}}=7.3\left(\mathrm{q}\left(\mathrm{pK}_{\mathrm{a}}\right)=6.2 \cdot 10^{2}\right.$ мкмоль/г), установленная для исходного образца шлака, резко снижается после пропускания имитата раствора до q $\left(\mathrm{pK}_{\mathrm{a}}\right)=1.9 \cdot 10^{2}$ мкмоль/г $\left(\right.$ по $\left.\mathrm{Mn}^{2+}\right)$ и $0.5 \cdot 10^{2}$ мкмоль/г $\left(\right.$ по $\left.\mathrm{Fe}^{3+}\right)$, что подтверждает поглощение катионов $\mathrm{Fe}(\mathrm{III})$ и $\mathrm{Mn}(\mathrm{II})$ на бренстедовских основных центрах. 
Следует отметить, что высокое количество активных центров на поверхности этого материала определяется высокой дисперсностью (фракция <0.08 мм).

\section{Заключение}

Результаты анализа поверхностей пенобетона разных плотностей и доменного гранулированного шлака методом РЦА показали наличие сорбционных свойств у этих материалов по отношению к катионам $\mathrm{Fe}(\mathrm{III})$ и $\mathrm{Mn}(\mathrm{II})$, что подтверждается резким изменением концентраций активных центров в области бренстедовских оснований после пропускания модельного раствора.

Исследованные материалы фракцией 1.0-0.63 мм могут найти практическое применение в виде фильтрующих загрузок, выполняющих не только механическую очистку, но и сорбционную, в различных водоотводных сооружениях транспортного строительства [15]. В таких сооружениях сорбция будет происходить в динамических условиях. При этом, учитывая реальный уровень загрязнения такими КТМ как $\mathrm{Mn}^{2+}$ и $\mathrm{Fe}^{3+}[16]$, например, на железнодорожном транспорте, степень очистки поверхностных стоков с железнодорожного полотна будет составлять более $90 \%$.

\section{Список литературы}

1. Земцов А.Е., Кутузов И.В., Мартемьянов Д.Б., Пшеничникова В.В. // «Техника и технология нефтехимического и нефтегазового производства», Материалы 9-ой международной научно-технической конференции, 26-28 февраля 2019 г., Омск, 2019, С. 163.

2. Ашхотов О.Г., Ашхотова И.Б. // Журнал физической химии. 2019. Т. 93. № 4. С. 584-586.

3. Галий П.В., Яровец И.Р., Ненчук Т.Н., Мазур П. и др. // Хімія, фізика та технологія поверхні. 2018. Т. 9. № 1. С. 46-63.

4. Титов Л.А. // «Технические науки: проблемы и решения», сборник статей по материалам XXIX международной научнопрактической конференции. 19 ноября 2019 г. М. 2019. С. 95-99.

5. Нечипоренко А.П. Дисс. докт. хим. наук. Санкт-Петербург. 1995. 234 с.

6. Гридчин А.М., Ядыкина В.В. // Вестник Харьковского Начионального автомобильно-дорожного университета. 2008. Вып. 40. С. 13-16.

7. Шангина Н.Н., Сватовская Л.Б., Комохов П.Г., Латутова М.Н. и др. Инженернохимические проблемы пеноматериалов третьего тысячелетия. Санкт-Петербург. ПГУПС. 1999. 115 с.

8. Абу-Хасан М. Дис. докт. техн. наук. Санкт-Петербург. 2004. 252 с.
9. Сватовская Л.Б., Шершнева М.В., Байдарашвили М.М., Сычева А.М. и др. Эко- и геоэкозащита природно-техногенных систем. Теория и практика. Санкт-Петербург. ПГУПС. 2016. 62 с.

10. Байдарашвили М.М. Дисс. канд. техн. наук. Санкт-Петербург. 2001. 145 с.

11. Сахарова А.С. Новые исследования в материаловедении и экологии. Санкт-

Петербург. ПГУПС. 2010. 101 с.

12. Иконникова Л.П., Минакова Т.С., Нечипоренко А.П. // Журн. прикл. химии. 1990. T. 63. № 8. C. 1703-1714.

13. Методы атомно-адсорбционной спектрофотометрии. Унифицированные методы исследования качества воды. СЭВ Часть 1. 1987. $127 \mathrm{c}$.

14. Грег С., Синг К. Адсорбция, удельная поверхность, пористость. М. МИР. 1984. 310 c.

15. Сватовская Л.Б., Байдарашвили М.М., Сахарова А.С., Петряев А.В. // Транспортное строительство. 2012. № 2. С. 9-11.

16. Сахарова А.С., Савельева М.Ю. // Транспорт: проблемы, идеи, перспективы (Неделя науки-2011), сборник научных статей Секции молодых исследователей научнотехнической конференции студентов, аспирантов и молодых ученых. 12-27 апреля 2011 г. Санкт-Петербург. 2011. С. 63-65. 


\title{
The study of the sorption properties of materials using physico-chemical method of adsorption sites distribution
}

\author{
Baidarashvili Marina M., Sakharova Antonina S. \\ Emperor Alexander I St.Petersburg State Transport University, Department of "Engineering Chemistry \\ and Natural Science", St.Petersburg
}

Adsorption of a large set of indicators demonstrates the way adsorption sites are distributed on a solid surface according to their acid-base (donor-acceptor) properties. The adsorption sites distribution method (ASD method) allows for prediction of the selective adsorption of various substances on specific active sites. The aim of this paper is to determine the sorption properties of certain solid materials with respect to heavy metal cations (HMC), using the surface characteristics as determined by the ASD method and the nature of the contaminants.

The ASD method was used to study foam concrete of various initial densities and ground granulated blast-furnace slag. The distribution of the adsorption sites on the surface of the samples was analysed before and after the saturation of the ground samples with solutions containing Fe(III) and Mn(II).

The analysis demonstrates that there are two types of adsorption sites on the surface of the initial sample of foam concrete with the density of $300 \mathrm{~kg} / \mathrm{m}^{3}$. According to the proposed classification, these types correspond to Brønsted bases $\left(\mathrm{pK}_{\mathrm{a}}=6-10.5\right)$. The adsorption occurs precisely in this area, which is experimentally confirmed by a dramatic decrease in the number of such sites after the interaction of the sample with the solution containing the HMC. A large number of Brønsted acid and base adsorption sites were observed on the surface of the initial foam concrete sample with the density of $500 \mathrm{~kg} / \mathrm{m}^{3}$. The concentration of the active sites in the area of Brønsted bases decreased after the interaction of the sample with a solution containing iron ions, which means that the adsorption of iron ions occurred. At the same time, the number of Brønsted acids remained practically constant, which demonstrates the adsorption selectivity. The analysis of the nature of the ASD on the surface of ground granulated blast-furnace slag (initial and processed) showed that the intensity of the adsorption zones in the $\mathrm{pK}_{\mathrm{a}}=7.3$ site of the initial slag sample decreases sharply after the interaction with the solution. This proves that the HMC are adsorbed on the Brønsted core centres. The large quantity of active sites on the surface of the material is accounted for by high dispersion (fraction $<0.08$ $\mathrm{mm})$.

Thus, the analysis of the distribution of active sites on the examined samples surface according to their acid-base properties demonstrated that the ASD method, as a physico-chemical method of studying solid surfaces, can be used to predict the sorption properties of solid materials and expand their application field.

Keywords: adsorption sites distribution, Brønsted-Lewis sites, acid-base type, heavy metal ions, sorption properties, foam concrete, ground granulated blast-furnace slag.

\section{References}

1. Zemtsov A.E., Kutuzov I.V., Martemyanov D.B., Pshenichnikova V.V., "Technique and technology of petrochemical and oil and gas production", Proceedings of the 9th International Scientific and Technical Conference, February 26-28, 2019, Omsk, 2019, p. 163.

2. Ashhotov O. G., Ashhotova I. B., J. of physical chemistry, 2019, Vol. 93, No 4, pp. 584-586.

3. Galiy P.V., Yarovets I.R., Nenchuk T.N., Mazur P. et al., Chemistry, physics and technology of surface, 2018, Vol. 9, No 1, pp. 46-63.

4. Titov L.A., "Technical sciences: problems and solutions", Proceedings of the XXIX International Scientific and Practical Conference, November 19, 2019, Moscow, 2019, pp. 95-99.

5. Nechiporenko A.P. Diss. doct. chem. nauk. St. Petersburg, 1995, 234 p.
6. Gridchin A.M., Yadykina V.V., Vestnik Khar'kovskogo Natsional'nogo avtomobil'nodorozhnogo universiteta, 2008, Vol. 40, pp. 1316.

7. Shangina N.N., Svatovskaya L.B., Komokhov P.G., Latutova M.N. et al., Inzhenernokhimicheskie problemy penomaterialov tret'ego tysyacheletiya. St. Peterburg, PGUPS, 1999, $115 \mathrm{p}$.

8. Abu-Khasan M. Diss. dokt. tekhn. nauk. St. Petersburg, 2004, 252 p.

9. Svatovskaya L.B., Shershneva M.V., Baidarashvili M.M., Sycheva A.M. etal., Eko- $i$ geoekozashchita prirodno-tekhnogennykh sistem. Teoriya i praktika. St. Peterburg, PGUPS, 2016, 62 p.

10.Baidarashvili M.M. Diss. kand. tekhn. nauk. St. Peterburg, 2001, 145 p. 
11. Sakharova A.S. Novye issledovaniya v materialovedenii i ekologii, St. Peterburg, PGUPS, 2010, $101 \mathrm{p}$.

12.Ikonnikova L.P., Minakova T.S., Nechiporenko A.P., Zh. adj. chemistry. 1990. Vol. 63, No 8. pp. 1703-1714.

13.Atomic absorption spectrophotometry methods. Unified methods for studying water quality. CMEA Part 1, 1987, 127 p.

14.Greg S., Sing K., Adsorption, specific surface area, porosity, M., MIR, 1984, $310 \mathrm{p}$.

Байдарашвили Марина Михайловна к.т.н., доцент кафедры «Инженерная химия и естествознание», Петербургский государственный университет путей сообщения Императора Александра I, Санкт-Петербург

Сахарова Антонина Сергеевна - к.т.н., доцент кафедры «Инженерная химия и естествознание», Петербургский государственный университет путей сообщения Императора Александра I, Санкт-Петербург
15.Svatovskaya L.B., Baidarashvili M.M., Sakharova A.S., Petriaev A.V., Transportnoe stroitel'stvo, 2012, No 2, pp. 9-11.

16.Sakharova A.C., Savel'eva M.Yu. Transport: problemy, idei, perspektivy (Nedelya nauki-2011), sbornik nauchnykh statei Sektsii molodykh issledovatelei nauchno-tekhnicheskoi konferentsii studentov, aspirantov i molodykh uchenykh, April 12-27, 2011, St. Peterburg, 2011, pp. 63-65.

Baidarashvili Marina M. - Ph.D., assistant professor, department of engineering chemistry and natural science, Emperor Alexander I St. Petersburg State Transport University (PGUPS), St. Petersburg, e-mail: assakharova@ list.ru

Sakharova Antonina S. - Ph.D., assistant professor, department of engineering chemistry and natural science, Emperor Alexander I St. Petersburg State Transport University (PGUPS), St. Petersburg, e-mail: assakharova@list.ru 